\title{
Endoscopic Management of Foreign Bodies in the Upper Gastrointestinal Tract in Yaoundé (Cameroon)
}

\author{
Antonin Wilson Ndjitoyap Ndam ${ }^{1,2 *}$, Akhenaton Ngock Dime1, \\ Servais Albert Fiacre Bagnaka Eloumou ${ }^{3}$, Tangie Ngek Larry ${ }^{1}$, Pierre Mathurin Kowo ${ }^{1}$, \\ Paul Talla ${ }^{2}$, Isabelle Dang Timba ${ }^{2,4}$, Bougha Georges ${ }^{5}$, Michèle Tagni-Sartre ${ }^{4}$, \\ Firmin Ankouane Andoulo ${ }^{1}$, Elie Claude Ndjitoyap Ndam ${ }^{1}$
}

\author{
${ }^{1}$ Department of Internal Medicine and Specialities, Faculty of Medicine and Biomedical Sciences, University of Yaoundé I, Yaoundé, \\ Cameroon \\ ${ }^{2}$ Hepatogastroenterology Unit, General Hospital, Yaoundé, Cameroon \\ ${ }^{3}$ Department of Clinical Sciences, Faculty of Medecine and Pharmaceutic Sciences, University of Douala, Douala, Cameroon \\ ${ }^{4}$ Hepatogastroenterology Unit, Cathedral Medical Center, Yaoundé, Cameroon \\ ${ }^{5}$ Hepatogastroenterology Unit, Jourdain Medical Center, Yaoundé, Cameroon \\ Email: *tonindam3@yahoo.fr
}

How to cite this paper: Ndjitoyap Ndam, A.W., Dime, A.N., Eloumou, S.A.F.B., Larry, T.N., Kowo, P.M., Talla, P., Timba, I.D., Georges, B., Tagni-Sartre, M., Andoulo, F.A. and Ndam, E.C.N. (2020) Endoscopic Management of Foreign Bodies in the Upper Gastrointestinal Tract in Yaoundé (Cameroon). Open Journal of Gastroenterology, 10, 247-255.

https://doi.org/10.4236/ojgas.2020.1010024

Received: August 26, 2020

Accepted: October 16, 2020

Published: October 19, 2020

Copyright ( 2020 by author(s) and Scientific Research Publishing Inc. This work is licensed under the Creative Commons Attribution International License (CC BY 4.0).

http://creativecommons.org/licenses/by/4.0/

\section{(c) (i) Open Access}

\begin{abstract}
Background/Aims: Foreign body (FB) ingestion is a common clinical situation. In some cases, it could be life-threatening, requiring interventional digestive endoscopy. Knowing the main FBs observed could help to prevent their ingestion or to improve management. The aim of this study is to report the results of upper digestive endoscopies performed for ingestion of FBs in Yaoundé (Cameroon). Methods: We recorded all patients who did a gastroscopy for FB ingestion from January 2000 to April 2020 in three medical centers of Yaoundé. We collected data concerning the socio-demographic characteristics of patients, foreign body type, endoscopic management and outcome. Results: A total of 9380 upper digestive endoscopies were performed, with $51 \mathrm{FBs}$ ingestion $(0.54 \%)$. Male were 27 (52.9\%). The mean age was $25.8 \pm 22.3$ years ( 8 months to 75 years). Coins were the most frequent FB (23.5\%), only observed in children, followed by fishbones (17.6\%), only observed in adults. We also observed dental wears (11.8\%), metallic objects (11.8\%), non-metallic objects (3.9\%), batteries (3.9\%), toothpick (2\%), packet of tablets (2\%), and bezoars (2\%). The FB was unknown at $21.6 \%$. The most frequent localization was the esophagus in 29/36 patients (80.5\%). Endoscopic removal was a success in $35 / 36$ patients (97.2\%). A surgery has been performed on one patient. We didn't register any death. Conclusion: Most common FBs ingested in Yaoundé are coins and fishbones. The upper digestive endoscopy has a high success rate.
\end{abstract}




\section{Keywords}

Endoscopic Management, Foreign Bodies, Upper Gastrointestinal Tract, Yaoundé

\section{Introduction}

Ingestion of foreign body (FB) is a frequent clinical situation [1]. In some cases, it could be life-threatening: it is an emergency [2] [3] [4]. The Ingestion could be accidental or intentional [5]. The type of FB is variable: coin, fishbones, batteries, wear dentures, razor blades, body packing, keys, toys, with difference between children and adults [6] [7] [8]. Some FBs could come out alone with feces, but some others could be trapped inside the oropharynx, the respiratory or digestive tract at gastrointestinal angulations or narrowing [9]. Clinical signs and/or radiological exam could show the site of impaction [2] [3] [4] [10]. The FB needs to be mobilized to come out alone, or removed through interventional endoscopy [5] [11]. Removing the FB could injure the mucosa: thus a real challenge for endoscopists [12] [13]. In case of failure, surgery can be necessary [7]. Due to inadequate resources, few studies have described the management of ingested FB in the gastrointestinal tract in central Africa. Data available is old or done on FBs in the laryngo-tracheobronchial tract [14] [15] [16]. Having an idea on the epidemiology of ingested FBs in the gastrointestinal tract in our area could help to prevent their onset, and also to improve their management. We herein describe the epidemiology, the etiology, the management and the outcome of ingested FBs in the upper digestive tract in three digestive endoscopic centers in Yaoundé (Cameroon).

\section{Methodology}

We conducted a descriptive retrospective study from January 2000 to April 2020 (20 years) in digestive endoscopic units of three medical centers of Yaoundé: the Yaoundé General Hospital, the "Centre Medical la Cathedrale", and the "Centre Medical le Jourdain". We retained all the endoscopic reports of patients seen for ingestion of FB. We did not include incomplete files. Data collected included socio-demographic characteristics (gender, age), circumstance of ingestion, clinical manifestations, the delay between the ingestion and the endoscopic exam, the type of $\mathrm{FB}$, site of impaction, mucosa lesions observed respecting the type of $\mathrm{FB}$, and the endoscopy result. In the upper digestive tract, the site of impaction of the FB could be the esophagus, the stomach or the duodenum. Concerning the mucosa lesions, they were classified on absence or presence. If present, the lesion could be mild in case of a little inflammation, intermediate in case of an erosion/ulceration, or severe in case of bleeding. We also assessed patient outcome. The endoscopist was always a senior endoscopist. Device used was a video-endoscope Fujinon $^{\circledR}$ or Olympus ${ }^{\oplus}$ depending on the centre. We also made use of radiologic 
investigations such as x-rays. Data were analyzed using SPSS version 20.0. Qualitative variables were presented as frequencies and percentages. We obtained administrative authorization from these three medical centers while an ethical clearance was procured from the ethical committee of the Faculty of Medicine and Biomedical Sciences of University of Yaoundé I.

\section{Results}

A total of 9380 upper digestive endoscopies were registered during our study period. We had 51 cases of FB ingestion representing $0.54 \%$.

We found 27 male (52.9\%) and 24 female (47.1\%). The mean age was $25.8 \pm$ 22.3 years ( 8 months to 75 years). Patients aged less than 15 represented $47.1 \%$ (Table 1).

The delay between ingestion of the FB and upper endoscopy was less than 24 hours in $43 / 51$ patients $(84.3 \%)$. At the time of digestive endoscopy, the FB was still localized at the upper digestive tract in $36 / 51$ patients $(70.6 \%)$ and the $\mathrm{FB}$ was already passed alone in other patients (29.4\%) (Table 2).

When ingested materials were still present, they were found in the esophagus in $29 / 36$ patients $(80.5 \%)$, in the stomach in $6 / 36$ patients $(16.7 \%)$, and in the duodenum in $1 / 36$ patient $(2.8 \%)$. The latter was the case of a toothpick observed in a 45 years old woman and was removed through endoscopy. Digestive endoscopy enabled extraction of 28/36 (77.8\%) of these FBs, $7 / 36$ (19.4\%) were pushed into the stomach to come out with feces, and digestive endoscopy didn't allow mobilization or extraction for only one patient out of $36(2.8 \%)$. This was a dental wear impacted in the upper third of the esophagus in a 60 years old man with failure of removal through the endoscopic method. It is the only case for which a surgery was required.

FBs observed were variable: coins (23.5\%), fishbones (17.6\%), dental wear (11.8\%), metallic objects such as toys, screw, hook $(11.8 \%)$, other nonmetallic object as rubber band and plastic bottle cap (3.9\%), batteries (3.9\%), toothpick $(2 \%)$, packet of tablets $(2 \%)$, bezoars $(2 \%)$, or unknown $(21.6 \%)$. Coins were the most frequent and only seen in children. They were followed by fishbones only observed in adults, and dental wear most frequent in adults (Table 2). We did not find any case of body packing.

Table 1. Demographic characteristics.

\begin{tabular}{lcc}
\hline \multicolumn{1}{c}{ Variable } & Frequency & Percentage \\
\hline Gender & & \\
- Male & $27 / 51$ & $52.9 \%$ \\
- Female & $24 / 51$ & $47.1 \%$ \\
Age(years) & & \\
$-<5$ & $13 / 51$ & $25.5 \%$ \\
$-5-14$ & $11 / 51$ & $21.6 \%$ \\
$-15-64$ & $23 / 51$ & $45.1 \%$ \\
$->65$ & $4 / 51$ & $7.8 \%$ \\
Mean: $25.8 \pm 22.3$ years & & \\
\hline
\end{tabular}


Table 2. Endoscopic results.

\begin{tabular}{|c|c|c|c|c|}
\hline & $\begin{array}{c}\text { Children } \\
(<15 \text { years }) n=24\end{array}$ & $\begin{array}{l}\text { Adults } \\
\mathrm{n}=27\end{array}$ & Total & Percentage \\
\hline \multicolumn{5}{|l|}{ Type of foreign bodies } \\
\hline - Coins & 12 & 0 & $12 / 51$ & $23.5 \%$ \\
\hline - Fishbones & 0 & 9 & $9 / 51$ & $17.6 \%$ \\
\hline - Dental wear & 1 & 5 & $6 / 51$ & $11.8 \%$ \\
\hline - Other metallic objects & 4 & 2 & $6 / 51$ & $11.8 \%$ \\
\hline - Batteries & 2 & 0 & $2 / 51$ & $3.9 \%$ \\
\hline - Other non metallic objects & 2 & 0 & $2 / 51$ & $3.9 \%$ \\
\hline - Toothpick & 0 & 1 & $1 / 51$ & $2 \%$ \\
\hline - Packet of tablets & 0 & 1 & $1 / 51$ & $2 \%$ \\
\hline - Bezoars & 0 & 1 & $1 / 51$ & $2 \%$ \\
\hline - Unknown & 3 & 8 & $11 / 51$ & $21.6 \%$ \\
\hline \multicolumn{5}{|l|}{ Delay for endoscopy } \\
\hline - Less than 24 hours & 23 & 20 & $43 / 51$ & $15.7 \%$ \\
\hline - More than 24 hours & 1 & 7 & $8 / 51$ & $84.3 \%$ \\
\hline \multicolumn{5}{|l|}{$\begin{array}{l}\text { Presence or absence of foreign body in the } \\
\text { upper digestive tract }\end{array}$} \\
\hline - Absence & 4 & 11 & $15 / 51$ & $29.4 \%$ \\
\hline - Presence & 20 & 16 & $36 / 51$ & $70.6 \%$ \\
\hline \multicolumn{5}{|l|}{ Site } \\
\hline - Esophagus & 14 & 15 & $29 / 36$ & $80.5 \%$ \\
\hline - Stomach & 6 & 0 & $6 / 36$ & $16.7 \%$ \\
\hline - Duodenum & 0 & 1 & $1 / 36$ & $2.8 \%$ \\
\hline \multicolumn{5}{|l|}{ Mucosa lesions } \\
\hline - None & 10 & 7 & $17 / 51$ & $33.3 \%$ \\
\hline - Mild inflammation & 4 & 6 & $10 / 51$ & $19.6 \%$ \\
\hline - Erosion/ulceration & 10 & 12 & $22 / 51$ & $43.1 \%$ \\
\hline - Bleeding & 0 & 2 & $2 / 51$ & $3.9 \%$ \\
\hline \multicolumn{5}{|l|}{ Outcome } \\
\hline - Success of endoscopic extraction & 17 & 11 & $28 / 36$ & $77.8 \%$ \\
\hline - Success of endoscopic mobilization & 6 & 1 & $7 / 36$ & $19.4 \%$ \\
\hline $\begin{array}{l}\text { - Failure of endoscopic extraction and } \\
\text { mobilization }\end{array}$ & 0 & 1 & $1 / 36$ & $2.8 \%$ \\
\hline
\end{tabular}

The ingestion was declared as voluntary in only one case over 51 (2\%). It was a case of ingestion of a packet of tablets by a 38 years old female in an attempt for autolysis. The FB was seen in the esophagus. Endoscopy enabled the packet to be pushed in the stomach which later came out with feces.

During endoscopy, operators described mucosa lesions due to the FB as: absent in $17 / 51$ (33.3\%), mild inflammation in $10 / 51$ patients (19.6\%), intermediate in $22 / 51$ patients $(43.1 \%)$ and severe in $2 / 51$ patients (3.9\%). Intermediate and severe lesions were often due to fishbone (Figure 1) and dental wear (Figure 2).

When the FB was metallic, an x-ray was sometimes done to identify its location in the digestive tract. We observed the case of a female child aged of twenty-two months who swallowed some parts of a blade. The upper digestive endoscopy, performed one day later, didn't find this object. The abdominal $\mathrm{x}$-ray 


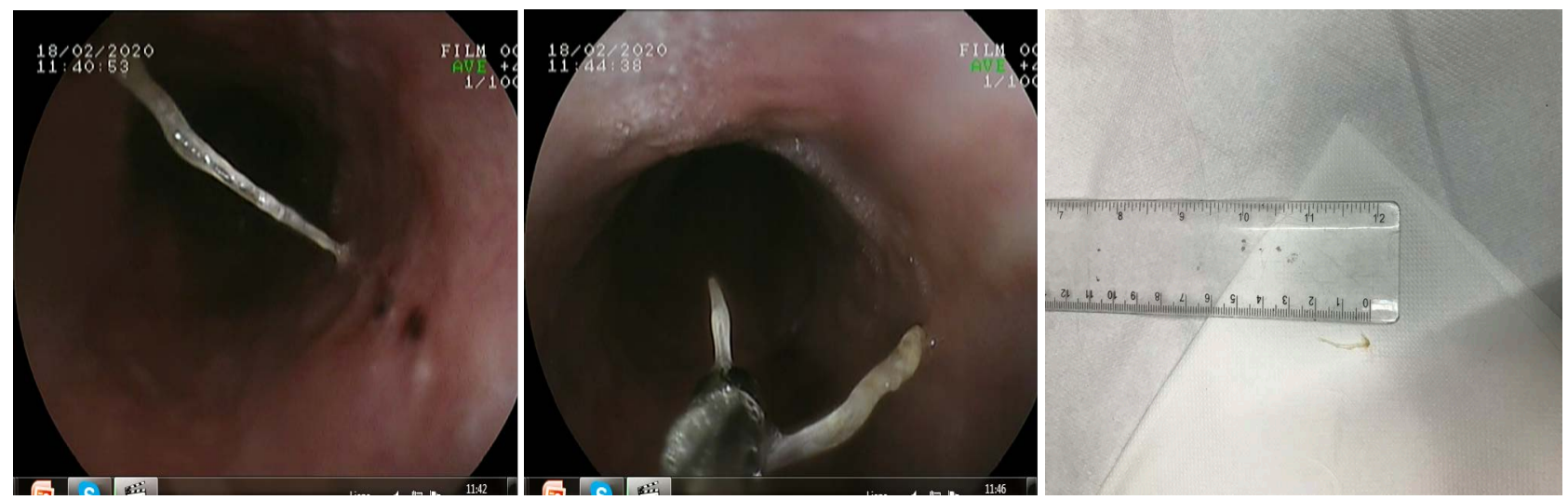

Figure 1. An ingested fishbone impacted in the upper third of the esophagus.

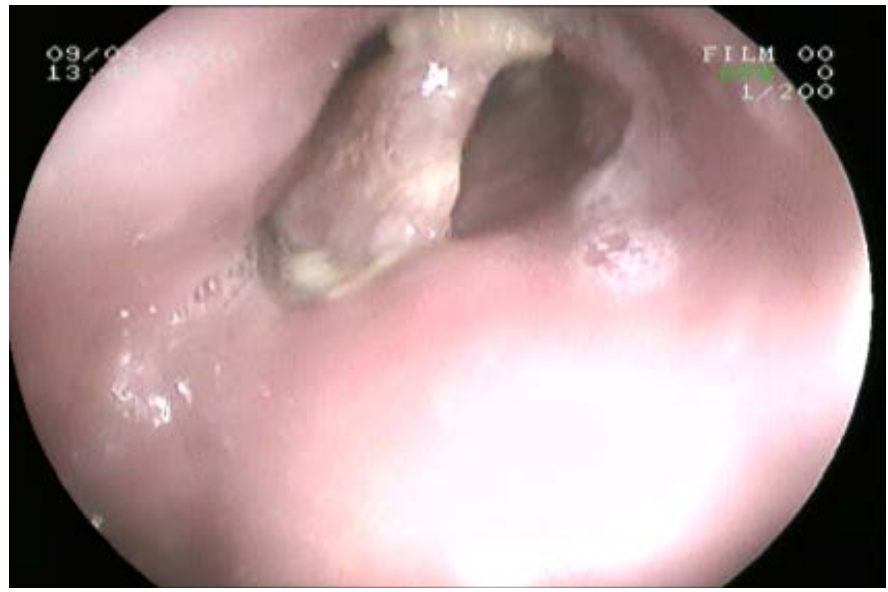

Figure 2. An ingested wear denture remove in the esophagus of a patient aged 66.

showed that it was localized in the small intestine (Figure 3). Two days later, these materials were ejected alone with feces with neither symptoms nor mucosa lesion of the upper digestive tract (Figure 4).

\section{Discussion}

We conducted a retrospective study to describe the epidemiology and management of FB in gastrointestinal tract. Retrospective studies increase the risk of missing data, but the low incidence of ingestion of FB doesn't enable the realization of prospective studies. During our period of twenty years of recruitment, we have only identified 51 cases which represent $0.54 \%$ of gastroscopies. A similar study conducted in Slovenia between January 1994 and January 2018 (14 years). Over 13,196 patients were investigated, giving a prevalence of $1.3 \%$ of true FB detected [5]. FB ingestion is rare indication of upper digestive tract endoscopy.

Despite our efforts, we cannot give the real incidence of ingested FB. It is due to the fact that most of them come out alone [1]. The American Society for Gastrointestinal Endoscopy (ASGE) estimated that $80 \%$ of FB pass out alone with feces [9]. Another reason is the fact that ENT (Ears, Nose, Throat) and chest medicine specialists remove many FBs which are localized in the oropharynx, 


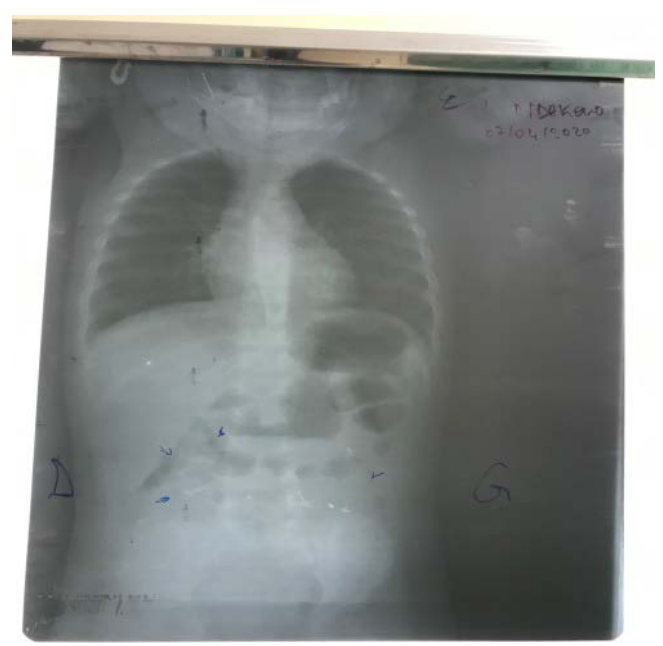

Figure 3. A thoraco-abdominal x-ray showing some parts of a razor blade inside the small intestine of an infant aged which later came out alone in feces.

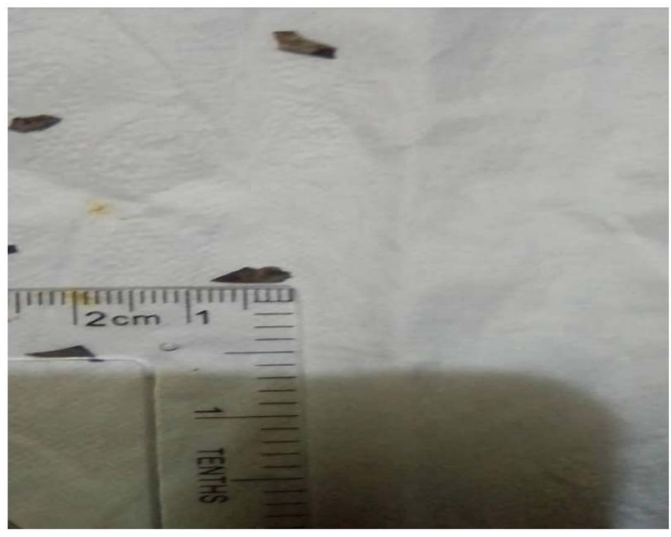

Figure 4. Blade remains in feces.

trachea-bronchia and also in the upper esophageal areas [16]. In case of perforation, the patient is treated by surgeons [7]. They do not associate gastroenterologists most of the time.

The sex ratio in our study was 1.1 . Gender varies from one study to the other. It was 1.75 in Mali between 2011 and 2014, but 0.6 in Taiwan between 2008 and 2016 [2] [17]. Probably the male gender is not a real risk factor of ingestion of FB.

We didn't observe the same FB in children and adults. In children, coins were the most observed. This observation was the same in studies conducted in other countries in the world [6] [12] [18]. Other FBs in children were metallic objects as toys, screw and hock, or batteries. We have to sensitize parents to in order to keep coins and other little object far from children. In adults, FB was mostly fishbones as observed in other reports (Figure 1) [1]. They were followed by and dental wear (Figure 2). They could remain impacted in the digestive tract, cause mucosa injuries with risks of perforation (picture 1). It is an emergency. A rapid endoscopy reduces the risk of the onset of complications [2]. Severe mucosa le- 
sions as bleeding were rare, same as in other studies [5]. During the intervention, sharped object could wound the mucosa. To reduce the risk of these injuries, some endoscopists use an overtube or reworked transparent cap [4] [19]. This material is not available in our centers. We observed few complications and didn't register any case of death.

Upper endoscopy was generally performed less than 24 hours after the ingestion as recommended [4]. But the FB was still the gastrointestinal tract only in $70.6 \%$ patients. This result confirms the theory which suggests that most of FBs come out alone. It is probably the case of many children. If no one sees them swallowing the FB, they could expel them with feces without any symptom or sign. A spectacular case is probably the child who swallowed some parts of a razor blade and expelled them with feces without any symptoms or lesion (picture 3 ). But the evolution would not have been the same if the FB passed through the respiratory tract. They would have developed symptoms such as cough and difficulties in breathing (penetration syndrome) which could be life threatening [15] [16].

The ingestion was generally accidental, except the case of a woman who voluntarily ingested a packet of tablets in an attempt of autolysis. Suicide attempts are more common in women, but the substance ingested is mainly caustic fluid. Drug ingestions are the next one in our setting [20].

When the FB was still in the digestive tract, it was mainly in the esophagus, the first portion of the upper digestive tract. This observation was the same in other studies [2] [18]. We observed a case of one FB in the duodenum. This localization is rare. It could be explained by the fact that, when the FB is already in the duodenum, it can come out alone through feces.

Endoscopy was successful to remove or to mobilize FBs in most of cases 35/36. It is a good exam to manage ingestion of FBs in the upper digestive tract. This good result has also been observed in other studies [12] [18] [19]. Only one case required surgery. Surgery increases the morbidity, but could be necessary [7].

\section{Limitations of the Study}

The retrospective nature of the study reduced the number of cases included due to incomplete files. Still due to the retrospective nature of the study complete information socio-demographic characteristics couldn't be obtained.

\section{Conclusion}

The ingestion of FB is rare but sometimes observed in upper digestive tract endoscopies. Etiologies are mostly coins in children, and fishbones in adults. Endoscopy was safe and effective to remove or to mobilize the objects in most of the cases.

\section{Acknowledgements}

The authors are thankful to the medical staff of these three endoscopic units. 


\section{Conflicts of Interest}

The authors declare no conflicts of interest regarding the publication of this paper.

\section{References}

[1] Bekkerman, M., Sachdev, A.H., Andrade, J., Twersky, Y. and Iqbal, S. (2016) Endoscopic Management of Foreign Bodies in the Gastrointestinal Tract: A Review of the Literature. Gastroenterology Research and Practice, 2016, Article ID: 8520767. https://doi.org/10.1155/2016/8520767

[2] Lee, C.Y., et al. (2019) Retrospective Analysis of Endoscopic Management of Foreign Bodies in the Upper Gastrointestinal Tract of Adults. Journal of the Chinese Medical Association, 82, 105-109. https://doi.org/10.1097/JCMA.0000000000000010

[3] Chen, T., Wu, H.-F., Shi, Q., Zhou, P.-H., Chen, S.-Y., Xu, M.-D., Zhong, Y.-S. and Yao, L.-Q. (2013) Endoscopic Management of Impacted Esophageal Foreign Bodies. Diseases of the Esophagus, 26, 799-806. https://doi.org/10.1111/j.1442-2050.2012.01401.x

[4] Birk, M., Bauerfeind, P., Deprez, P.H., Häfner, M., Hartmann, D., Hassan, C., Hucl, T., Lesur, G., Aabakken, L. and Meining, A. (2016) Removal of Foreign Bodies in the Upper Gastrointestinal Tract in Adults: European Society of Gastrointestinal Endoscopy (ESGE) Clinical Guideline. Endoscopy, 48, 489-496. https://doi.org/10.1055/s-0042-100456

[5] Skok, P. and Skok, K. (2020) Urgent Endoscopy in Patients with "True Foreign Bodies" in the Upper Gastrointestinal Tract-A Retrospective Study of the Period 1994-2018. Zeitschrift für Gastroenterologie, 58, 217-223. https://doi.org/10.1055/a-1062-9011

[6] Tang, L.J., et al. (2018) Clinical Features and Prognosis of Gastrointestinal Injury Due to Foreign Bodies in the Upper Gastrointestinal Tract in Children: A Retrospective Analysis of 217 Cases. Chinese Journal of Contemporary Pediatrics, 20, 567-571.

[7] Orji, F.T., Akpeh, J.O. and Okolugbo, N.E. (2012) Management of Esophageal Foreign Bodies: Experience in a Developing Country. World Journal of Surgery, 36, 1083-1088. https://doi.org/10.1007/s00268-012-1510-7

[8] Nijhawan, S., et al. (1995) Unusual Foreign Bodies of Upper Gastrointestinal Tract. Tropical Gastroenterology, 16, 50-52.

[9] Ikenberry, S.O., et al. (2011) Management of Ingested Foreign Bodies and Food Impactions. Gastrointestinal Endoscopy, 73, 1085-1091.

https://doi.org/10.1016/j.gie.2010.11.010

[10] Marco de Lucas, E., Sádaba, P., Lastra García-Barón, P., Ruiz-Delgado, M.L., González Sánchez, F., Ortiz, A. and Pagola, M.Á. (2004) Value of Helical Computed Tomography in the Management of Upper Esophageal Foreign Bodies. Acta Radiologica, 45, 369-374. https://doi.org/10.1080/02841850410005516

[11] Yuan, F.F., Tang, X.W., Gong, W., Su, L. and Zhang, Y.L. (2018) Endoscopic Management of Foreign Bodies in the Upper Gastrointestinal Tract: An Analysis of 846 Cases in China. Experimental and Therapeutic Medicine, 15, 1257-1262. https://doi.org/10.3892/etm.2017.5561

[12] Sugawa, C., Ono, H., Taleb, M. and Lucas, C.E. (2014) Endoscopic Management of Foreign Bodies in the Upper Gastrointestinal Tract: A Review. World Journal of Gastrointestinal Endoscopy, 6, 475-481. https://doi.org/10.4253/wjge.v6.i10.475 
[13] Xu, D., Li, Q.L. and Zhou, P.H. (2019) The Safety and Feasibility of Endoscopic Treatment for Upper Gastrointestinal Tract Foreign Bodies in Elderly Patients Over 80 Years Old. Chinese Journal of Contemporary Pediatrics, 22, 1078-1081.

[14] Kpemissi, E., Diparidé Agbèrè, R., Ndakéna, K. and Késsié, K. (1997) Foreign Bodies of the Esophagus: Etiologic and Therapeutic Aspects. Experience at the CHU of Lomé (Togo). Sante, 7, 338-340.

[15] Kpemissi, E., Agbèrè, A., Kessie, K., Gnamey, K. and Assimadi, K. (1995) Laryngeal, Tracheal and Bronchial Foreign Bodies in Togo: Diagnostic and Therapeutic Problems. Médecine Tropicale (Mars), 55, 395-396.

[16] Nyeki, A.R., et al. (2015) Laryngo-Tracheobronchial Foreign Bodies: Experience of the Teaching Hospital of the Armed Forced Omar Bongo Ondimba Libreville. The Pan African Medical Journal, 20, Article 298. https://doi.org/10.11604/pamj.2015.20.298.4576

[17] Togo, S., et al. (2017) Management for Esophageal Foreign Bodies: About 36 Cases. The Pan African Medical Journal, 27, 207.

[18] Khurana, A.K., et al. (1998) Management of Foreign Bodies of the Upper Gastrointestinal Tract. Tropical Gastroenterology, 19, 32-33.

[19] Zhang, S., et al. (2010) Endoscopic Management of Foreign Bodies in the Upper Gastrointestinal Tract in South China: A Retrospective Study of 561 Cases. Digestive Diseases and Sciences, 55, 1305-1312.

https://doi.org/10.1007/s10620-009-0900-7

[20] Lawson-Ananissoh, L.M., et al. (2014) Endoscopic Aspects of Toxic Ingestions during Attempted Suicides at Lome Campus Teaching Hospital (Togo). Médecine et Santé Tropicales, 24, 432-434. https://doi.org/10.1684/mst.2014.0390 